University of Nebraska - Lincoln

DigitalCommons@University of Nebraska - Lincoln

3-18-2008

\title{
Experimental characterization of the impact-damage tolerance of a cross-ply graphite-fiber/epoxy laminate
}

\author{
Xiang-Fa Wu \\ Department of Engineering Mechanics, University of Nebraska-Lincoln, xfwu@unlserve.unl.edu \\ Goutam Ghoushal \\ University of Nebraska - Lincoln \\ Mikhail Kartashov \\ University of Nebraska - Lincoln \\ Zuleyha Aslan \\ Cumhuriyet University, Sivas 58140, Turkey \\ Joseph A. Turner \\ University of Nebraska - Lincoln, jaturner@unl.edu \\ See next page for additional authors
}

Follow this and additional works at: https://digitalcommons.unl.edu/engineermechwu

Part of the Mechanical Engineering Commons

Wu, Xiang-Fa; Ghoushal, Goutam; Kartashov, Mikhail; Aslan, Zuleyha; Turner, Joseph A.; and Dzenis, Yuris A., "Experimental characterization of the impact-damage tolerance of a cross-ply graphite-fiber/epoxy laminate" (2008). Xiang-Fa Wu Publications. 1.

https://digitalcommons.unl.edu/engineermechwu/1

This Article is brought to you for free and open access by the Mechanical \& Materials Engineering, Department of at DigitalCommons@University of Nebraska - Lincoln. It has been accepted for inclusion in Xiang-Fa Wu Publications by an authorized administrator of DigitalCommons@University of Nebraska - Lincoln. 


\section{Authors}

Xiang-Fa Wu, Goutam Ghoushal, Mikhail Kartashov, Zuleyha Aslan, Joseph A. Turner, and Yuris A. Dzenis 
Published in Polymer Composites 29:5 (2008) , pp. 534- 543; doi 10.1002/pc.20373

Copyright (C) 2008 Society of Plastics Engineers; published by John Wiley \& Sons, Inc.

http://www.interscience.wiley.com Used by permission.

Research funded by the U.S. Army Research Laboratory and the U.S. Air Force Office of Scientific Research.

Published online March 18, 2008

\title{
Experimental characterization of the impact-damage tolerance of a cross-ply graphite-fiber/epoxy laminate
}

\author{
Xiang-Fa Wu ${ }^{1}$, Goutam Ghoshal ${ }^{1}$, Mikhail Kartashov ${ }^{1}$, Zuleyha Aslan ${ }^{2}$, \\ Joseph A. Turner ${ }^{1}$, Yuris A. Dzenis ${ }^{1}$ \\ ${ }^{1}$ Department of Engineering Mechanics, Center for Materials Research and Analysis, \\ University of Nebraska-Lincoln, Lincoln, Nebraska 68588-0526 \\ ${ }^{2}$ Department of Mechanical Engineering, Cumhuriyet University, Sivas 58140, Turkey \\ Email: Xiang-Fa Wu - xfwu@unlserve.unl.edu; Joseph A. Turner - jaturner@unl.edu; Yuris A. Dzenis - ydzenis@unl.edu \\ Corresponding author: Xiang-Fa Wu, Department of Engineering Mechanics, Center for Materials Research and Analysis, \\ University of Nebraska-Lincoln, Lincoln, Nebraska 68588-0526
}

\begin{abstract}
In this study, the impact-damage tolerance of a graphite-fiber/epoxy composite laminate is studied by examining the correlation between the impact force and the resulting delamination area in the laminate. The cross-ply $\left[0_{2} / 90_{2} / \mathrm{O}_{2}\right]_{\mathrm{S}}$ composite laminate was made of thermosetting P7051S-20Q-1000 prepregs (Toray Composites America). A Hopkinson pressure bar (HPB) was employed to create the impulsive loading with varying magnitude. Transient impact force, displacement, impact power, and transmitted impact energy were calculated using the transient signals recorded from the strain gage mounted on the HPB. Impulsive loads with controllable magnitude were used to induce delamination damage with varying size in the composite samples. Nondestructive evaluation based on a novel ultrasonic pulse-echo reflector technique was used successfully for characterizing the delamination areas in the thin composite samples with thickness $\sim 2 \mathrm{~mm}$. The present experimental results indicate that there exists a very good linear correlation between the impact force (e.g. the peak force, impact impulse, peak impact power, and the transmitted impact energy of the first impact force pulse exerted by the HPB) and the delamination area of the composite samples. This correlation can be used to determine the threshold of the impact force that initiates the delamination damage in the composite laminate. In contrast to the weight-drop test, the present experimental method successfully examined the impact damage tolerance of polymer matrix composites (PMCs) subjected to impulsive loading with very high force magnitude and ultra short duration such as the typical ballistic impact. The present method and results can be used for the study of impact damage tolerance of PMCs with varying lay-ups and interface modifications.
\end{abstract}

\section{Introduction}

Fiber-reinforced polymer matrix composites (PMCs) made of high modulus fibers in relatively low modulus polymeric matrices have found extensive applications in aerospace and aeronautical structures, ground vehicles, and offshore and marine constructions due to their high specific stiffness and strength, excellent fatigue tolerance, great resistance to corrosion, etc. These properties have resulted in substantial research on the manufacturing and mechanical properties of PMCs since the 1960s [1]. As a matter of fact, PMCs are microscopically heterogeneous. Their mechanical properties are highly susceptible to internal damage that may be induced by localized impact under various stressing conditions, e.g. impact of aircraft wings imparted by a dropped tool or flying runway debris. Usually, such localized damage may be undetectable by regular visual inspection; however, it may lead to significant detriment to the stiffness and strength, durability, and stability of the PMC structures. Therefore, it is desirable to explore efficient experimental methods to characterize the damage evolution in PCMs subjected to localized impulsive loadings and relevant correlation between damage size and impact forces. So far, considerable effort has been made to understand the strain rate effect on the damage behavior of PMCs for better design and more reliable lifetime prediction of PMC-based structures [2- 5, and refs therein].

Among a variety of instrumental impact testing methods, the low-velocity weight-drop impact test has been used extensively for the characterization of the impact damage tolerance of PMCs in the past two decades [6-23]. In 
Table 1. Mechanical properties of the unidirectional composite used here (No. 2500-250F curable epoxy) [27].

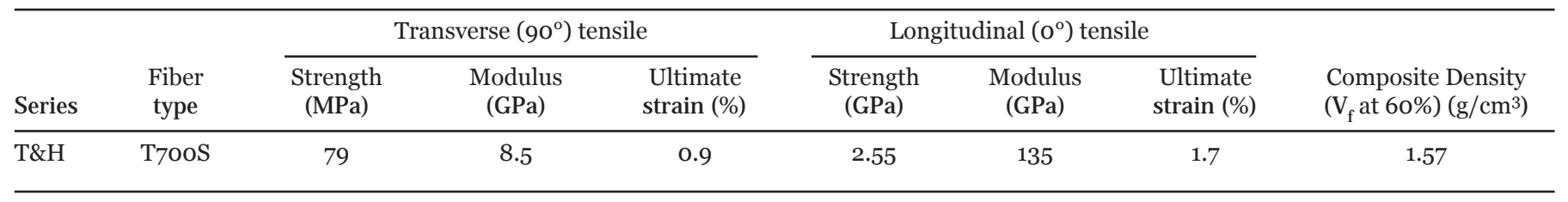

such test based on the weight-drop scheme, the impactor is made of a stiff high-strength alloy striker mounted on a heavy metallic block. The impactor is accelerated by its own weight released from several heights in the test. Useful data available in such a test include the force-time curve and the kinetic energy loss of the impactor. After an impact test, impact-induced damage of the PMC samples can be examined by means of nondestructive evaluation (NDE) techniques such as the commonly used soft X-ray photography and ultrasonic C-scan, among others. Because of the specific structure of the impactor, the variation of impact force versus time recorded in a typical test usually involves multiple force peaks that are induced by the propagation and reflection of the stress waves inside the impactor. The impedance mismatch of the composite specimen and the impactor may further amplify this effect. Therefore, the actual impact event in a low-velocity weight-drop test is a typical multiple-impact. In such a test, the maximum value of the impact force occurs after quite a few sub-peaks of the impact force in the impact event. This makes the actual impact event much more complex to analyze and characterize. Furthermore, because of the large amount of impactor mass, a substantial part of the kinetic energy of the impactor is transferred into the strain energy of the composite specimen in terms of large elastic deformation and vibration. In fact, use of simple kinetic energy loss of the impactor to characterize the damage tolerance of composite laminates may lead to appreciable deviation for comparison among different specimen configurations and testing machines. On the other hand, impact damage in composite laminates caused by small, stiff masses such as flying runway debris or projectiles is characterized as an impact with very high force taking place in a very short interval of time. Therefore, the common low-velocity impact tests may not be suitable for the study of the impact tolerance of composite laminates subjected to such impulsive loadings. Recently, a few investigations have been performed to take into account the delamination damage of composite laminates subjected to ballistic impact and ultrashort impulsive force exerted by a Hopkinson pressure bar (HPB) system [24-26]. In an attempt to exploit this experimental method for the design of composite structures with targeted impact damage tolerance subjected to ballistic impact, further study in this topic is still needed. For instance, the correlation between the delamination size and the impulsive force has not been fully explored so far, though it plays a crucial role in examining the damage evolution in composite laminates subjected to external impact.
Considering the above issues, in the present study, we focused our attention on the damage tolerance evolution in a graphite-fiber/epoxy laminate subjected to impulsive loading through a HPB system. The HPB system used here has its unique characteristics. First, the impact force of the HPB can be exactly recorded through a strain gage sensor mounted on the HPB, and the peak value of the first impact force pulse is always the maximum in an entire impact event. This peak value is much greater than those induced in other testing methods such as the typical weight-drop test. Second, there is a significant interval of time between two neighboring impact force pulses that can be controlled by selecting proper length of the HPB; therefore, the interference of two neighboring impact force pulses can be suppressed effectively. Actually, in such a case, the impact force pulses that follow the first one have limited effect on the impact damage event. After each test, the peak impulsive force, peak impact power, impulse, and transmitted impact energy of the HPB can be determined by analyzing the recorded data. After the impact test, NDE based on ultrasonic C-scan technique can be conducted to characterize the damage size of the failed composite samples. Because of the low thickness of the composite laminate $(\sim 2$ $\mathrm{mm}$ ), the delamination damage was unable to be detected using a traditional ultrasonic C-scan technique. Therefore, a modified C-scan technique, the pulse-echo reflector technique (PERT), was further developed and utilized successfully for detecting the delamination damage. Experimental results were used to correlate the delamination area of the composite samples with the peak impulsive force, impact impulse, peak impact power, and transmitted impact energy, respectively. The correlation results were used to determine the impact-damage tolerance of the composite laminate. Finally, conclusions and potential applications of the present study are addressed.

\section{Experimental Procedures}

\section{Specimen Design and Preparation}

A cross-ply thermal-setting graphite-fiber/epoxy composite laminate made of 12-layer Toray P7051S-20Q1000 prepregs was fabricated. The unidirectional prepregs consisted of T70oS graphite fibers in a F250 resin system with typical areal weight $312 \mathrm{~g} / \mathrm{m}^{2}$. Mechanical properties of the unidirectional laminate were provided by the manufacturer (Toray Composites America) [27] and have also 


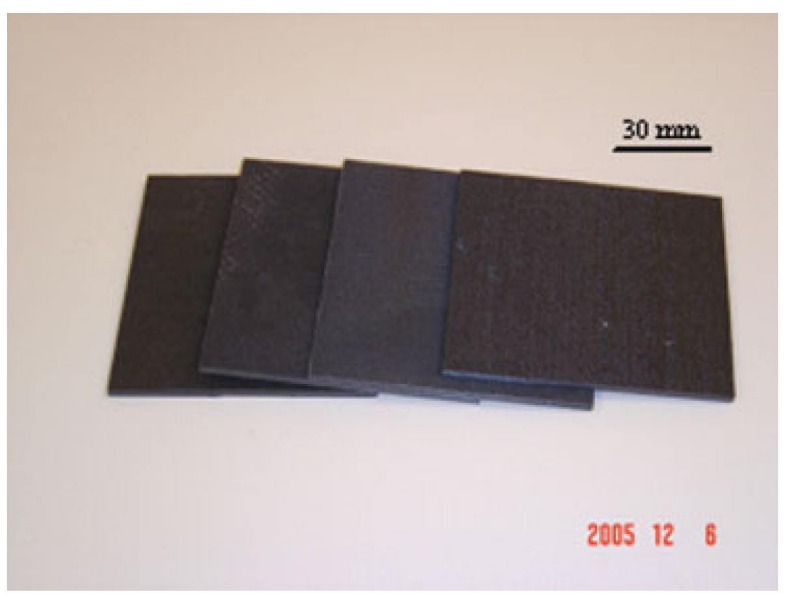

Figure 1. Cross-ply polymer composite samples used for the experimental investigation. (P7051S-20Q-1000 graphite-fiber/epoxy prepregs provided by the Toray Composites America, lay-up: $\left[\mathrm{O}_{2} / 9 \mathrm{O}_{2} / \mathrm{O}_{2}\right]_{\mathrm{s}^{\prime}}$ dimensions: $\sim 2 \times 90 \times 90$ in $\mathrm{mm}$.)

been used in our previous studies [28-30], as tabulated in Table 1.

During the process, cross-ply-laminated panels with a lay-up of $\left[\mathrm{O}_{2} / 9 \mathrm{O}_{2} / \mathrm{O}_{2}\right]_{\mathrm{S}}$ were assembled following a hand lay-up procedure and cured in a two-chamber pressclave under controlled temperature, pressure, and vacuum environment in accordance with the manufacturerrecommended curing cycle [27-29]. The thickness of the laminate is around $2 \mathrm{~mm}$ after curing. The typical laminate samples used in the test had dimensions: $\sim 2 \times 90 \times$ 90 (in $\mathrm{mm}$ ), as shown in Figure 1. The specimen fixture used for the impact test was made of two square steel plates (dimensions: $12.25 \times 165 \times 165$ in $\mathrm{mm}$ ) with a central opening (dimensions: $55 \times 55$ in $\mathrm{mm}$ ), as shown inFigure 2a. During the impact test, the composite specimen
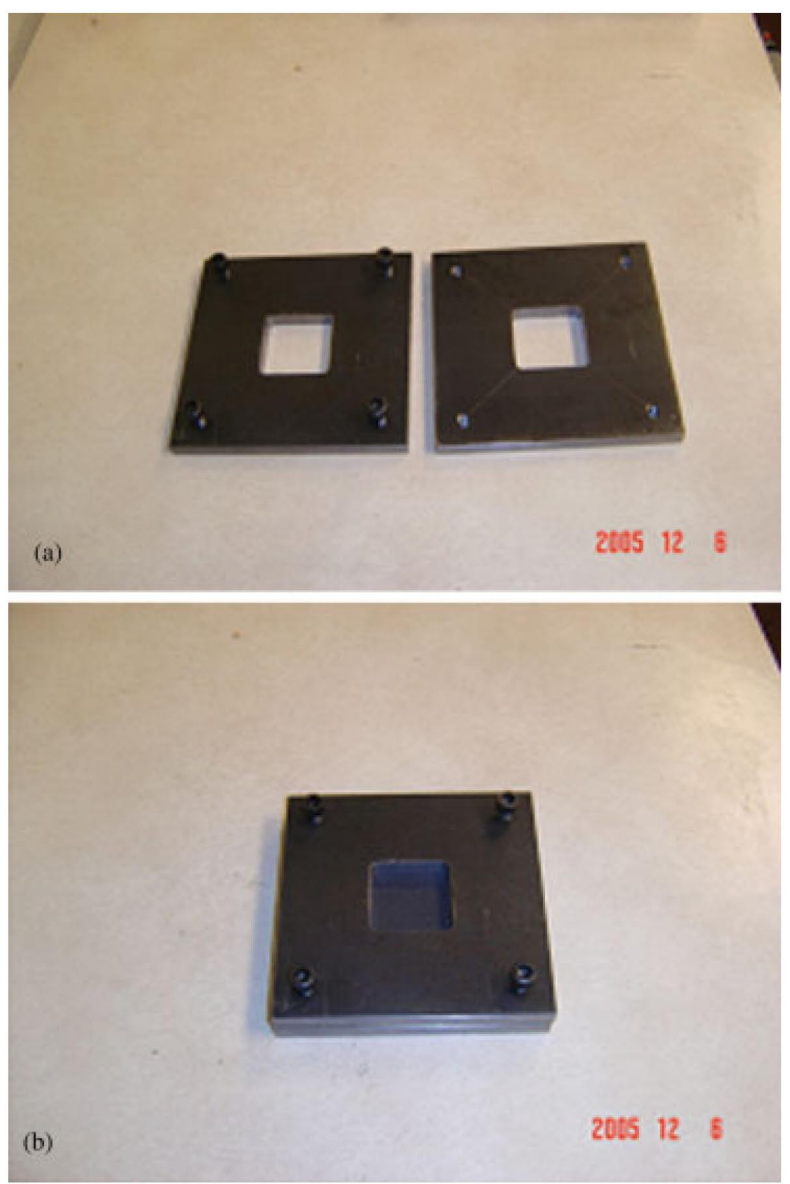

Figure 2. (a) Specimen fixture and (b) specimen-fixture assembly. (Fixture dimensions: $12.25 \times 165 \times 165$ in $\mathrm{mm}$; dimensions of the centered square opening: $50 \times 50$ in $\mathrm{mm}$.)

was centered and sandwiched between the two steel plates using four tie-down bolts at the corners. The specimenfixture assembly is shown in Figure $2 b$.

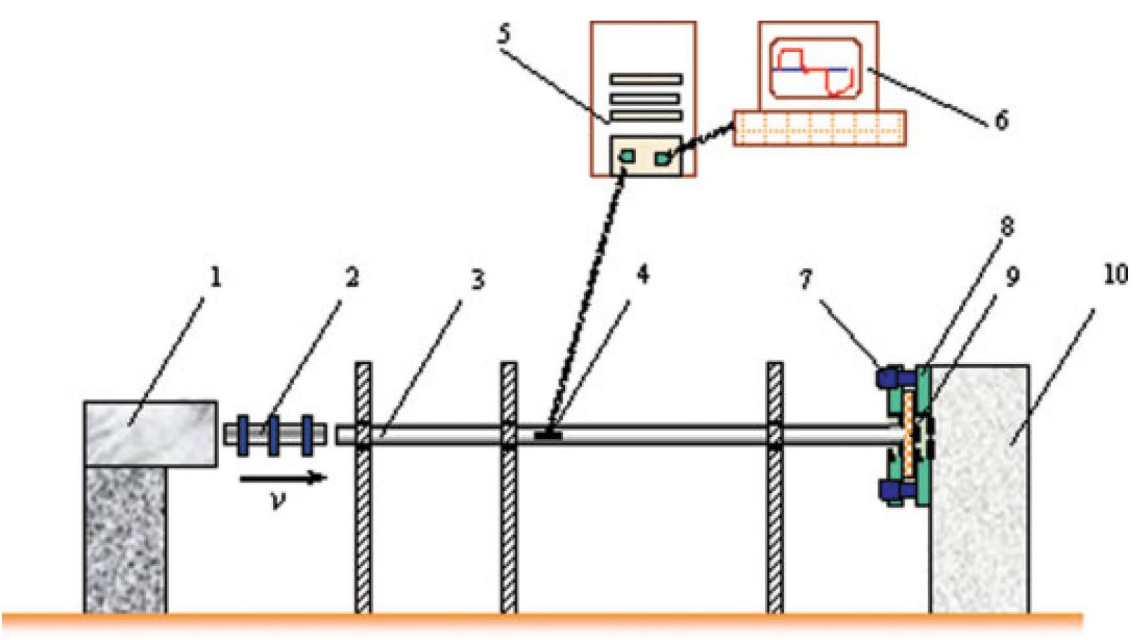

Figure 3. Schematic of the Hopkinson pressure bar (HPB) system. 1, Gas gun; 2, striker; 3, incident bar (with machined spherical end); 4, strain gage sensor; 5, digital oscillator; 6, computer; 7, tapped bolts; 8, steel plates; 9, composite specimen; 10, specimen-fixture supporter. 


\section{Impact Experimental Setup and Tests}

The impact-damage test was conducted on an experimental setup consisting of a gas gun, a circular highstrength steel striker of length $300 \mathrm{~mm}$, and a HPB of length $1,574 \mathrm{~mm}$, as illustrated in Figure $3[28,30]$. The diameter of both the steel striker and the HPB is $8 \mathrm{~mm}$. The materials of the striker and the HPB were the same in order to avoid the impedance mismatch during an impact event. The specimen-fixture assembly was fixed on the testing bench using two stiff heavy clamps, and the HPB with a spherical head was directed in contact with the center of the specimen through the square opening of the fixture (Figure 3). The impact force acting on the specimen was created by the impact of the striker bar on the HPB coaxially. The striker was propelled by compressed nitrogen gas in the gas gun chamber. Upon impact, a compressive stress pulse was generated in the HPB and propagated toward the specimen. The incident pulse on the specimen was partially reflected back into the bar and partially transmitted into the composite specimen. The magnitudes and durations of the incident and reflected pulses were recorded exactly using a strain gage sensor mounted in the middle of the HPB, as illustrated in Figure 3. The pulse that was transmitted from the HPB propagated inside the specimen, reflected at the specimen free-surfaces, and finally led to the delamination damage along the weak laminar interfaces. The signals of the stress wave propagating in the HPB were recorded by a high-resolution digital oscilloscope. The transient impact force, impulse acting on the specimen, and kinetic energy transferred were then determined using the recorded strain gage signals.

In this study, four values of nitrogen pressure in the gas gun chamber were used: 0.070 MPa ( 10 psi), $0.103 \mathrm{MPa}$ ( $\sim 15 \mathrm{psi}), 0.138 \mathrm{MPa}(\sim 20 \mathrm{psi})$, and $0.172 \mathrm{MPa}(\sim 25 \mathrm{psi})$, and the corresponding striker impact speeds ranged from 5 to $30 \mathrm{~m} / \mathrm{s}$. At each loading level, two duplicate tests were performed to show the repeatability of the present testing method.

\section{NDE of Laminate Delamination by Ultrasonic Pulse-Echo Reflector Technique}

Ultrasonic pulse-echo techniques have been employed extensively for NDE of layered materials for decades. Generally, the damage inside a material can be detected by means of the pulse-echo method through examining the backwall echo, the reflection from the back surface of the material. When the wave encounters any discontinuity inside the material, a peak appears earlier than the backwall echo. This peak amplitude and its time of arrival are generally used for detecting cracks and the depth of cracks. An image then can be constructed by scanning at different locations on the targeted material. However, when the thickness of the material layer is small (i.e. in the order of the wavelength of the incident wave) such as the composite laminate used in the present study with thickness only $\sim 2 \mathrm{~mm}$, the signal from the backwall coincides with the frontwall echo. Therefore, it becomes extremely difficult and usually impossible to separate the backwall echo from the frontwall echo. Thus, any signal reflected from a defect cannot be detected. In some cases, higher frequency signals may be utilized to decrease the wavelength, but higher frequencies are more sensitive to heterogeneities in the composite (e.g. fibers). In an attempt to eliminate these obstacles, in this study, a C-scan image was constructed using an ultrasonic PERT. In this case, an auxiliary reflector plate was placed under the composite laminate, as illustrated in Figure 4. During the test, a focused transducer with focal length of $\sim 75 \mathrm{~mm}$ in water was used, and the water path distance (WP) was adjusted such that the focal point of the transducer lies halfway $(\sim 1 \mathrm{~mm})$ inside the material. Under the condition of constant WP, the transducer movement in $\mathrm{X}$ and $\mathrm{Y}$ directions was controlled by stepper motors. The signals from the transducer were recorded by the control computer. With the PERT, the ultrasonic waves travel through the composite laminate and then reach the reflector plate. If there is a delamination inside the laminate, the ultrasonic wave will not be able to penetrate the laminate and reach the reflector. Therefore, the delamination inside the composite laminate can be detected by analyzing the signal received from the reflector plate.

\section{Data Reduction And Results}

The impact pressure acting on the specimen surface can be calculated from the HPB stress difference exerted by the incident wave and the first reflected wave. The transient stress in the HPB was determined following a simple Hooke's law relation such that $\sigma=E \varepsilon$ with E the Young's modulus of the HPB bar and $\varepsilon$ the instantaneous strain derived from the circuit relation of the half-bridge Wheatstone bridge circuit:

$$
\varepsilon=\frac{2 U}{S_{g} V_{0}}
$$

In Equation 1, $\mathrm{U}$ is the voltage measured from the strain gage sensor, $\mathrm{V}_{0}$ is the excitation voltage, and $\mathrm{S}_{\mathrm{g}}$ is the strain gage factor that is a constant. In this study, $\mathrm{V}_{0}=24 \mathrm{~V}$ and $\mathrm{S}_{\mathrm{g}}$ =2.04. Therefore, the impact force $F(t)$, the instantaneous displacement of the HPB head $u(t)$, the instantaneous impact power $\mathrm{P}(\mathrm{t})$, and the transmitted impact energy $\mathrm{W}(\mathrm{t})$ from the HPB can be determined by

$$
\begin{gathered}
F(t)=E A\left[\varepsilon_{\mathrm{i}}(t)+\varepsilon_{\mathrm{r}}(t)\right], \\
u(t)=c \int_{0}^{t}\left[\varepsilon_{\mathrm{i}}(t)-\varepsilon_{\mathrm{r}}(t)\right] d t, \\
P(t)=F(t) v(t)=E A c\left(\varepsilon_{\mathrm{i}}^{2}-\varepsilon_{\mathrm{r}}^{2}\right),
\end{gathered}
$$

and

$$
W(t)=\int_{0}^{t} F(t) v(t) d t=E A c \int_{0}^{t}\left[\varepsilon_{\mathrm{i}}^{2}-\varepsilon_{\mathrm{r}}^{2}\right] d t
$$




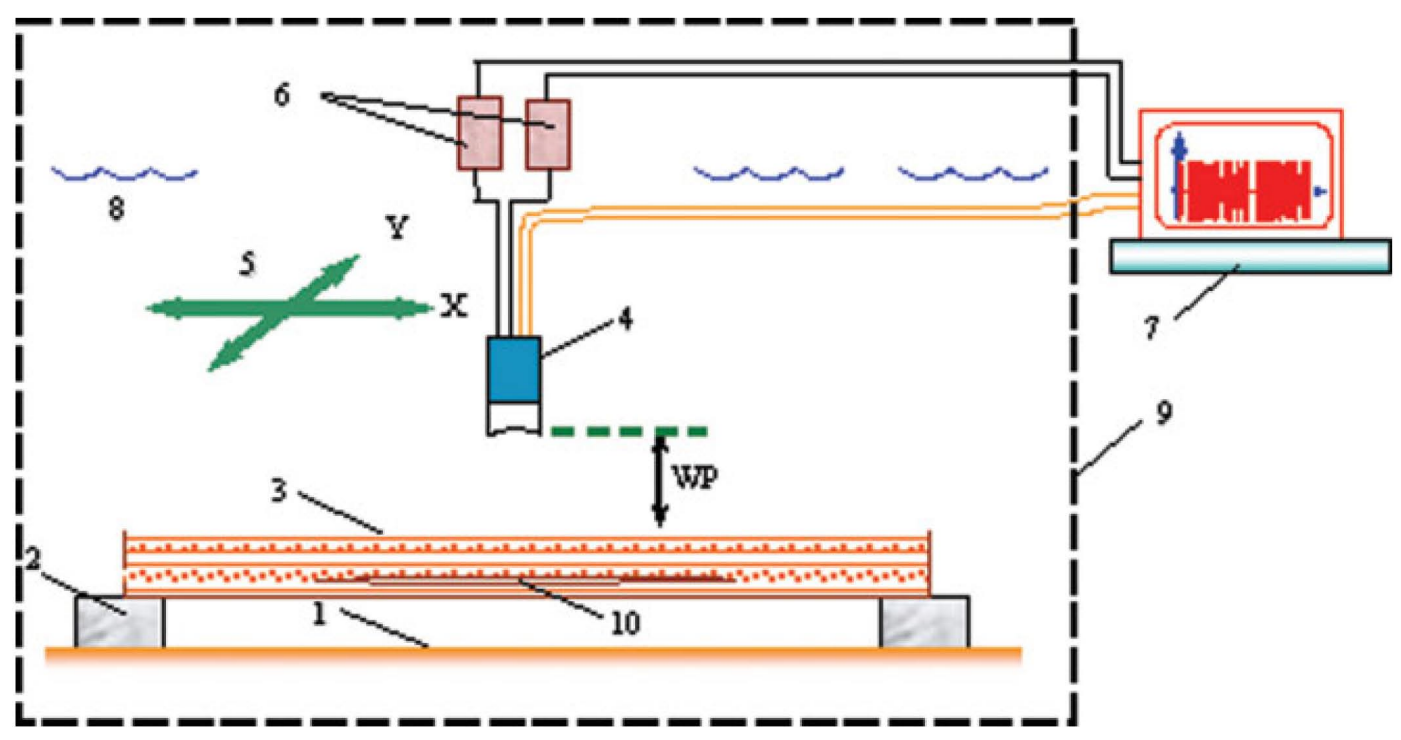

Figure 4. Schematic of the ultrasonic pulse-echo reflector technique (PERT). 1, Reflector plate; 2, supporter; 3, composite laminate; 4, ultrasonic-focused transducer; 5, transducer movement axes; 6, stepper motor; 7, computer; 8 , water surface; 9, water tank; 10, delamination damage.

Here, A is the cross-sectional area of the HPB $\left(50.27 \mathrm{~mm}^{2}\right)$; $\mathrm{v}(\mathrm{t})$ is the instantaneous velocity of the HPB head toward the specimen; $\varepsilon_{\mathrm{i}}(\mathrm{t})$ and $\varepsilon_{\mathrm{r}}(\mathrm{t})$ are respectively the transient strains of the HPB corresponding to the incident and reflected waves according to Equation 1 . $\mathrm{C}$ is the speed of the longitudinal wave in the HPB $(5,892 \mathrm{~m} / \mathrm{s}$, as determined by the experimental measurement).

In each impact test, to eliminate the spike-like dispersion wave that commonly occurs in high-speed impact tests using a HPB system, a soft thin material sheet ( $2 \mathrm{~mm}$ aluminum or copper sheet) was fixed to the head of the incident bar toward the striker bar. As a result, the typical incident stress-wave signal recorded from the HPB

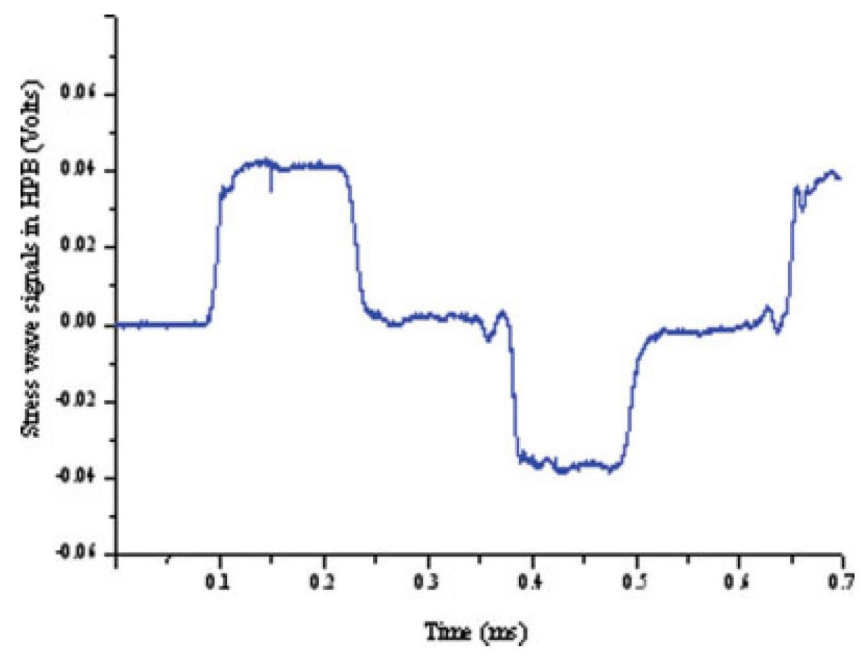

Figure 5. Typical stress-wave signals recorded in the HPB system. is shown in Figure 5. The typical impact force, calculated from the recorded strain signals by using Eq. 2, is shown in Figure 6. It is found that the maximum value of the impact force always occurs in the first impact force pulse and the peak values of the following force pulses decay rapidly. For a typical impact test performed in the present study, the peak force value of the second force pulse was $50 \%$ of the first one, and therefore the resulting transmitted impact energy of the second force pulse was only around $30 \%$ of the first one. Furthermore, there existed a significant interval of time between two neighboring impact force pulses, such that wave interference between two neighboring impact force pulses can be neglected. Therefore, the present

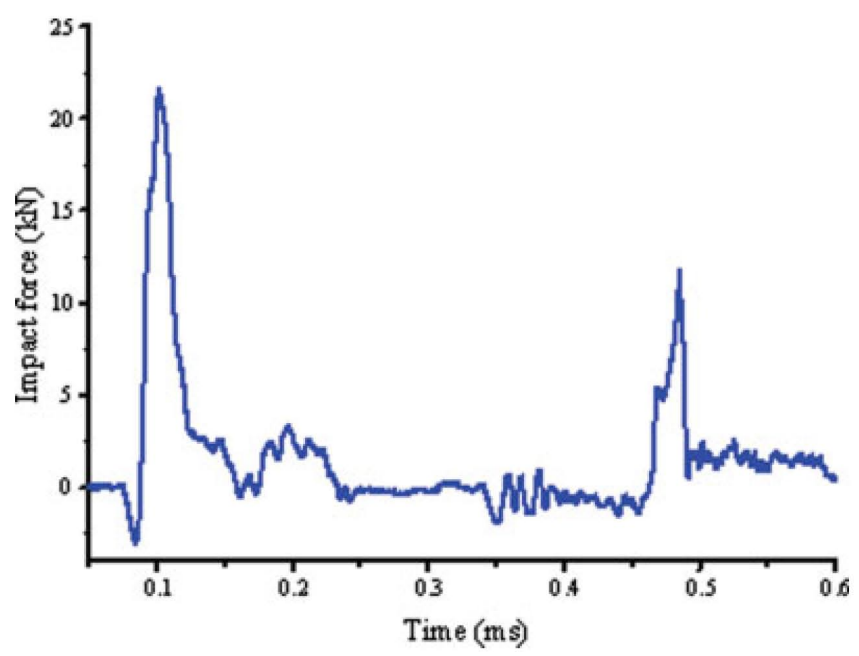

Figure 6. Typical impact force exerted by the HPB. 
(a)

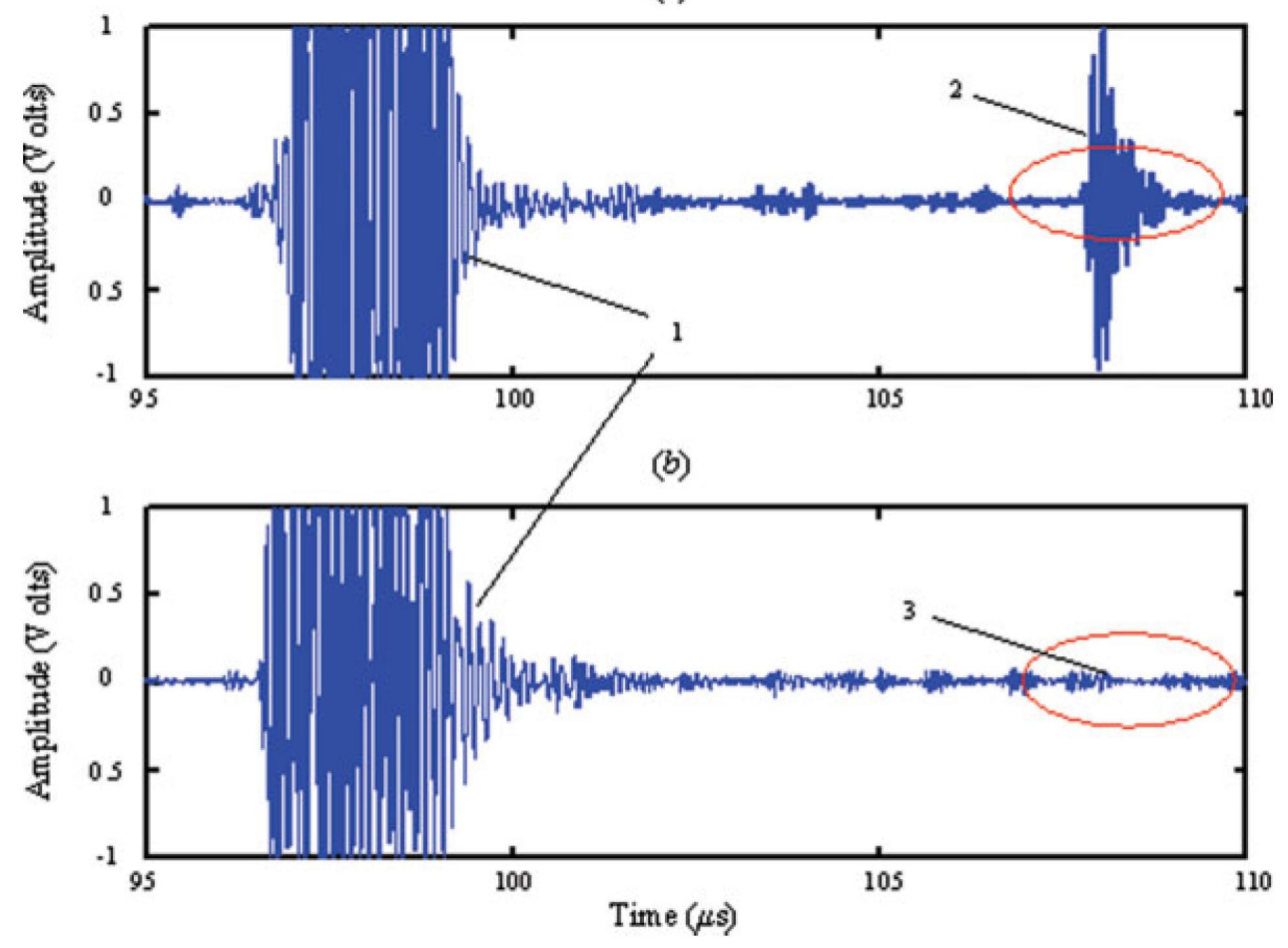

Figure 7. Typical ultrasonic reflection-wave signals recorded in the transducer for the laminated composite samples (a) without and (b) with delamination. 1, Reflection-wave signal from the composite laminate; 2 , reflection-wave signal from the reflector plate; 3 , weak signal from the reflector plate due to delamination damage.

impact test can be considered as a weakened multiple-impact test by comparison with the regular weight-drop test. In fact, for a regular weight-drop test, the force-time curve typically includes significant oscillations with very close peak forces and intervals that complicate the character- ization of the delamination initiation and damage mechanisms. Thus, it is reasonable to consider the correlation between the damage size and the first impact force pulse, such as its peak force, peak impact power, impulse, and transmitted impact energy.
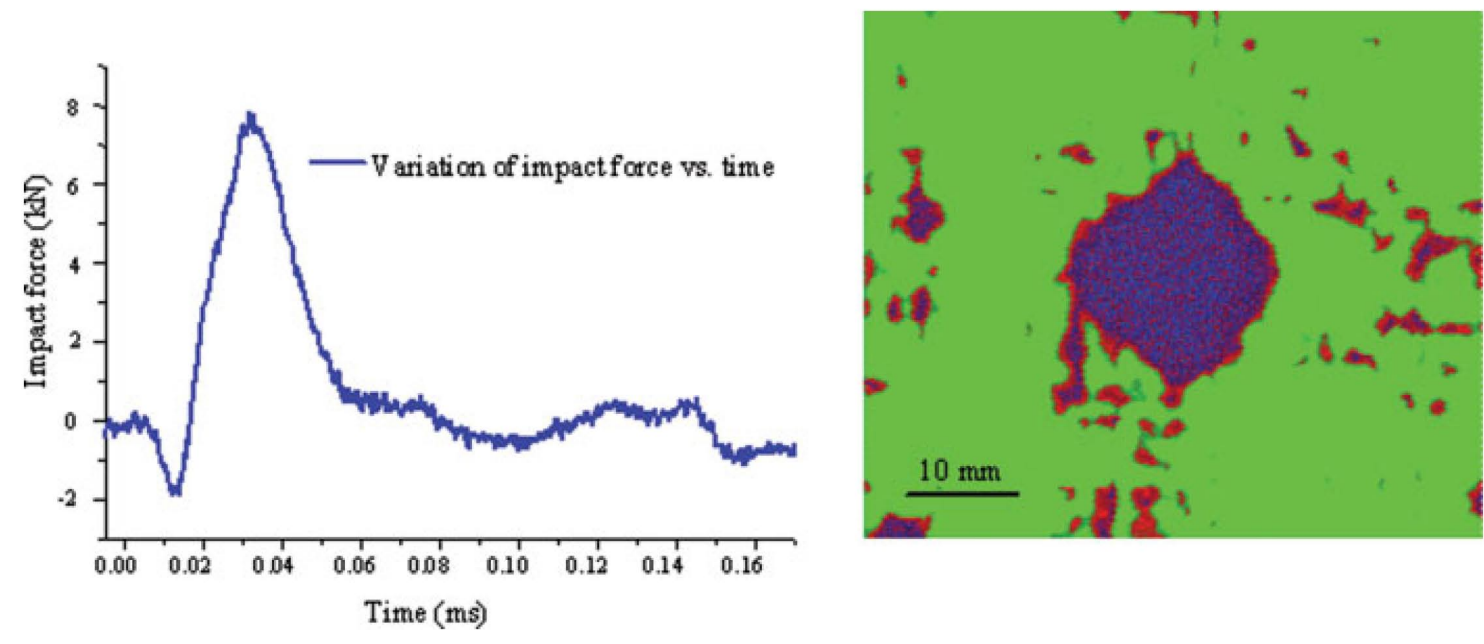

Figure 8. Impact torce and corresponding $\mathrm{C}$-scan image of delamination damage in the composite laminate (Sample-I). (Lay-up: $\left[\mathrm{O}_{2} / 9 \mathrm{O}_{2} / \mathrm{O} 2\right]_{\mathrm{S}}$, peak impact force: $7.83 \mathrm{kN}$, impulse: $0.135 \mathrm{Ns}$, peak impact power: $41.33 \mathrm{~kW}$, transmitted impact energy: $1.857 \mathrm{~J}$, delamination area: $\sim 230 \mathrm{~mm}^{2}$.) 

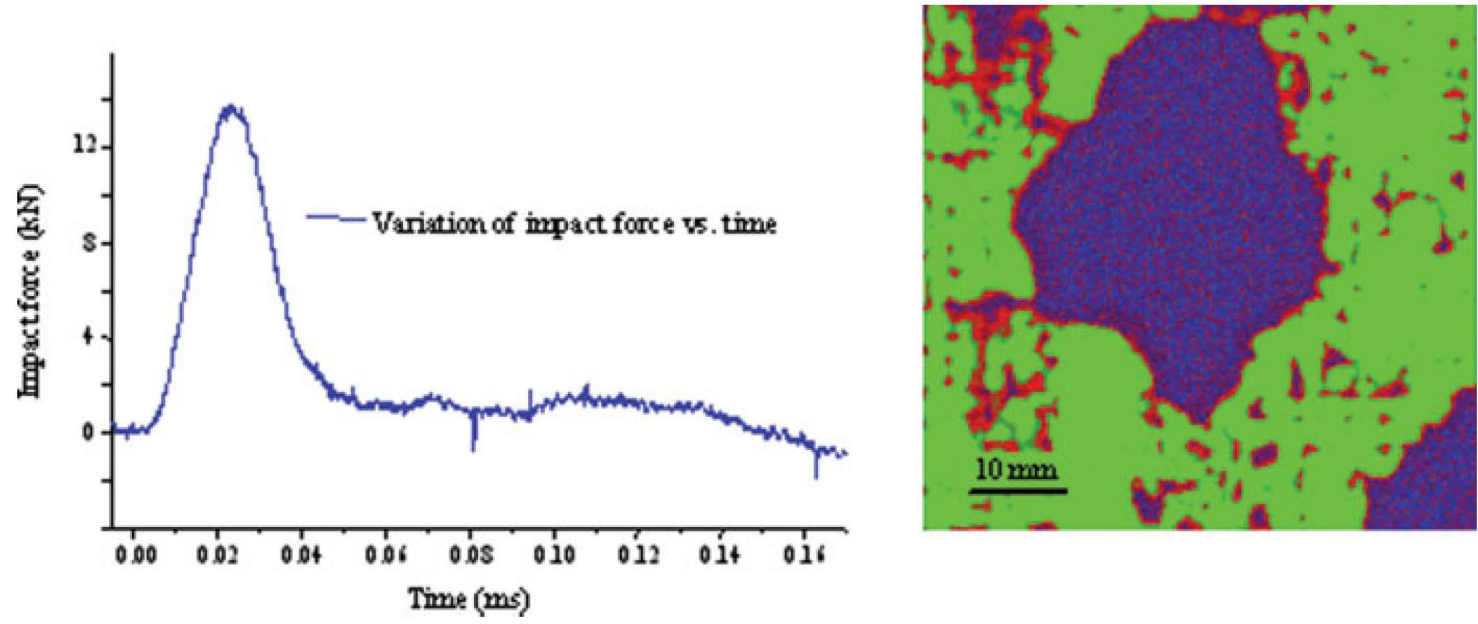

Figure 9. Impact force and corresponding C-scan image of delamination damage in the composite laminate (Sample-II). (Lay-up: $\left[\mathrm{O}_{2} / 9 \mathrm{O}_{2} / \mathrm{O}_{2}\right]_{\mathrm{s}}$, peak impact force: $13.80 \mathrm{kN}$, impulse: 0.425 N.s, peak impact power: $136.39 \mathrm{~kW}$, transmitted impact energy: $7.32 \mathrm{~J}$, delamination area: $\sim 740 \mathrm{~mm}^{2}$.)

Now let us consider the ultrasonic PERT for the characterization of the delamination damage in failed specimens. If there is a delamination in the composite laminate, the ultrasonic wave is unable to penetrate the laminate and reach the reflector. Thus, it would result in no signal or a very weak signal from the reflector. Typical ultrasonic signals recorded are shown in Figure $7 \mathrm{a}$ and $\mathrm{b}$. As shown in the figures, the backwall and frontwall echoes are mixed, and it is almost impossible to distinguish them. However, the reflection from the reflector is very clear when there is no delamination, and it disappears when the transducer is positioned at the delaminated area, as shown in Figure $7 \mathrm{a}$ and $\mathrm{b}$, respectively. As a result, the reflector echo is a good measure for the detection of delamination damage in composite laminate whose thickness is smaller than the incident wavelength. Consequently, the peak amplitude of the reflection from the reflector plate can be assigned a color to create the C-scan image of the composite laminate.

Figures 8-11 show variations of the impact force versus time of the first impact force pulse and the corresponding PERT-scan images for four typical specimens subjected to varying impact force levels, respectively. The delamination area in each specimen was approximated by counting the number of pixels occupied by the damage in the image with errors around $5 \%$ due to the ambiguous boundaries. The results show that subjected to relatively low-velocity impact (Figures 8 and 9) the impact forces grew smoothly in a very short interval of time ( $0.05 \mathrm{~ms})$ that corresponds to the delamination damage mainly along the $0^{\circ} / 90^{\circ}$ interfaces, i.e. the diamond-shaped damage as characterized by the PERT scans. In such a loading case given in Figure 8, no obvious damage can be observed visually near the HPB
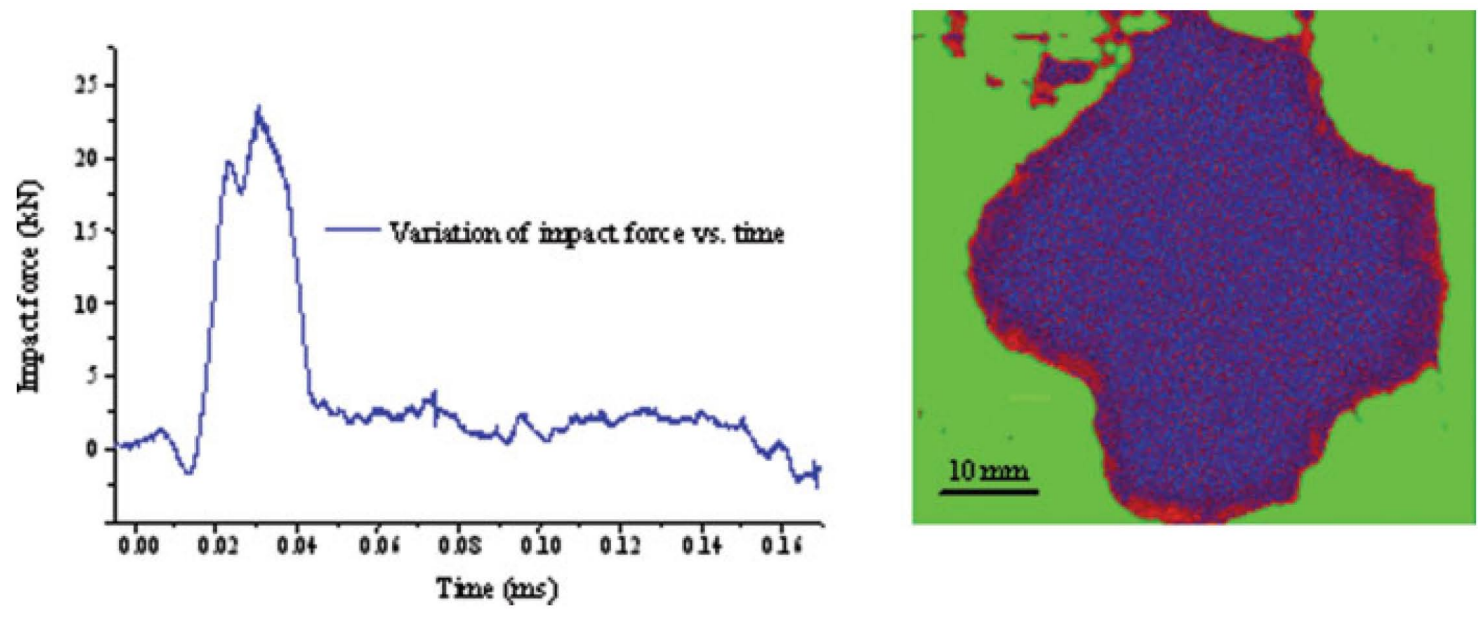

Figure 10. Impact force and corresponding C-scan image of delamination damage in the composite laminate (Sample-III) (Lay-up: $\left[\mathrm{O}_{2} / 9 \mathrm{O}_{2} / \mathrm{O}_{2}\right]_{\mathrm{s}}$, peak impact force: $23.49 \mathrm{kN}$, impulse: $0.658 \mathrm{~N} . \mathrm{s}$, peak impact power: $287.83 \mathrm{~kW}$, transmitted impact energy: $10.73 \mathrm{~J}$, delamination area: $\sim 1,390 \mathrm{~mm}^{2}$.) 

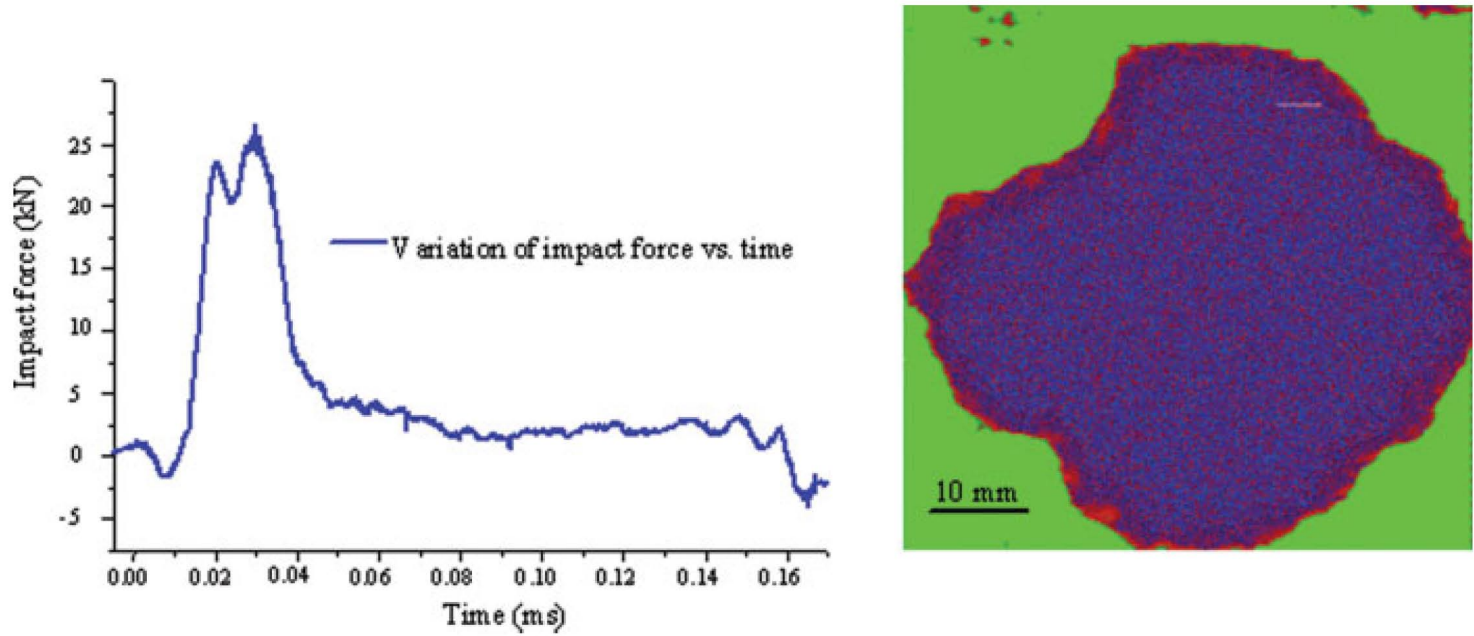

Figure 11. Impact force and corresponding C-scan image of delamination damage in the composite laminate (Sample-IV). (Lay-up: $\left[\mathrm{O}_{2} / 9 \mathrm{O}_{2} / \mathrm{O}_{2}\right]_{\mathrm{s}}$, peak impact force: $26.54 \mathrm{kN}$, impulse: 0.824 N.s, peak impact power: $424.93 \mathrm{~kW}$, transmitted impact energy: $16.00 \mathrm{~J}$, delamination area: $\sim 1,660 \mathrm{~mm}^{2}$.)

contact zone at the specimen surface by naked-eyes though delamination damage existed inside the laminate as detected by the PERT. However, in the loading case given in Figure 9, after impact a small dent with depth nearly onethird the thickness of the composite laminate can be found, and no further visible damage was detected at the specimen surface. Figure 12a shows the typical sample surface after the impact, which accords to the impulsive loading given in Figure 9. Furthermore, for impact with relatively high speeds (Figures 10 and 11), impact force jumps were observed. This indicates that the high impact forces have led to macroscopic cracking of the composite laminate along the fiber direction that resulted in the abrupt drop of the laminate stiffness, i.e. the sudden drop of the impact force as measured in the HPB system. This has been validated through examining the macroscopic cracks at the specimen surfaces. In the loading case given in Figure 11, Figure 12b shows the corresponding macroscopic cracking at a typical sample surface back to the HPB head.

As mentioned previously, the interval of two neighboring impact force pulses is $\sim 0.26 \mathrm{~ms}$, which is much greater than the duration of an impact force pulse that is $~ 0.05$ $\mathrm{ms}$; and the peak value of the first impact force pulse is also much greater than that of the subsequent ones. Therefore,

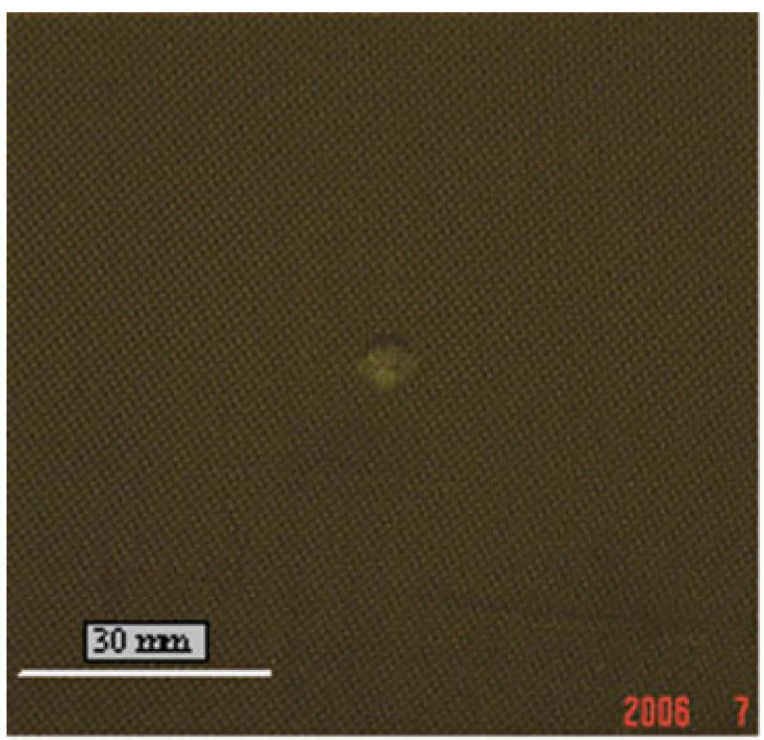

(a) Surface towards the HPB

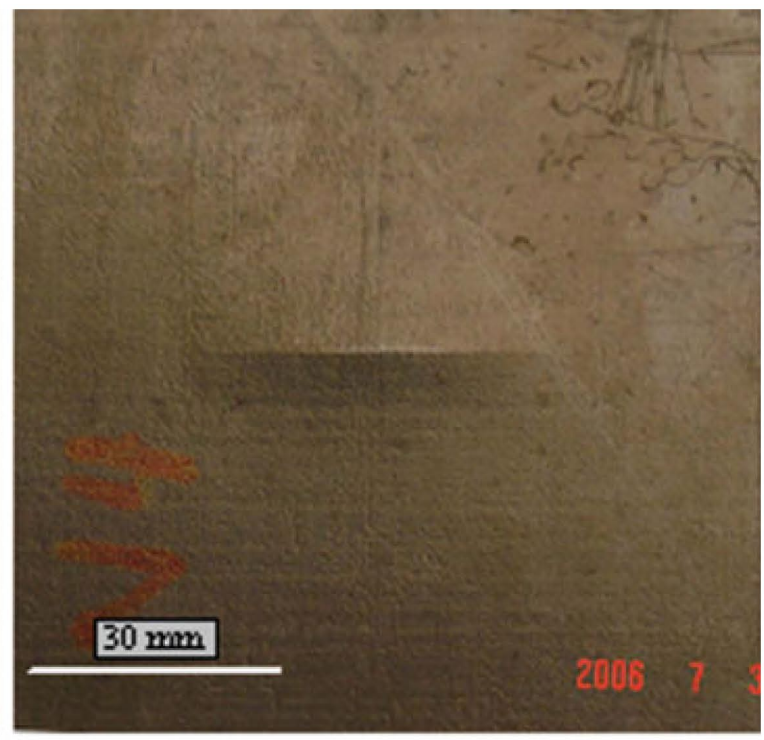

(b) SIfface opposte to the HPB

Figure 12. Macroscopic damage of the composite samples after impact. 


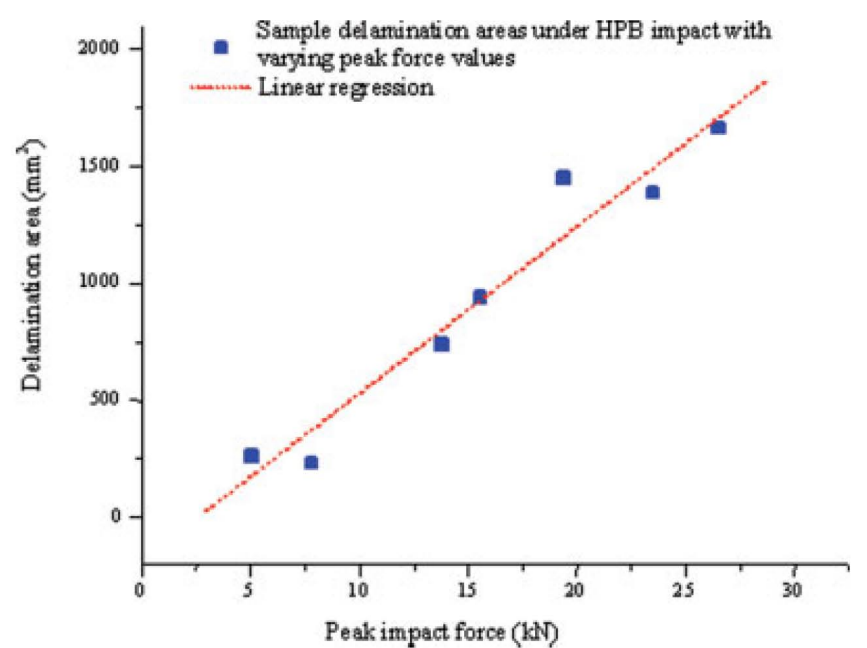

Figure 13. Variation of the sample delamination area versus the peak impact force.

the maximum damage size of the laminate is expected to correlate mainly with the first impact force pulse such that the contribution of the impact force pulses that followed after the first one can be ignored. Experimental data plotted in Figures 13-16 indicate a very good linear relationship between the delamination area and the peak impact force, peak impact power, impact impulse, and transmitted impact energy of the first impulse exerted by the HPB for a wide range of loadings, respectively. From Figures 15 and 16 , it can also be found that subjected to the present impulsive loadings the impact energy transmitted into the composite laminate is very low around $2-20 \mathrm{~J}$ because of the extremely short duration of each impact event. However, the transient peak value of the impact power is ex-

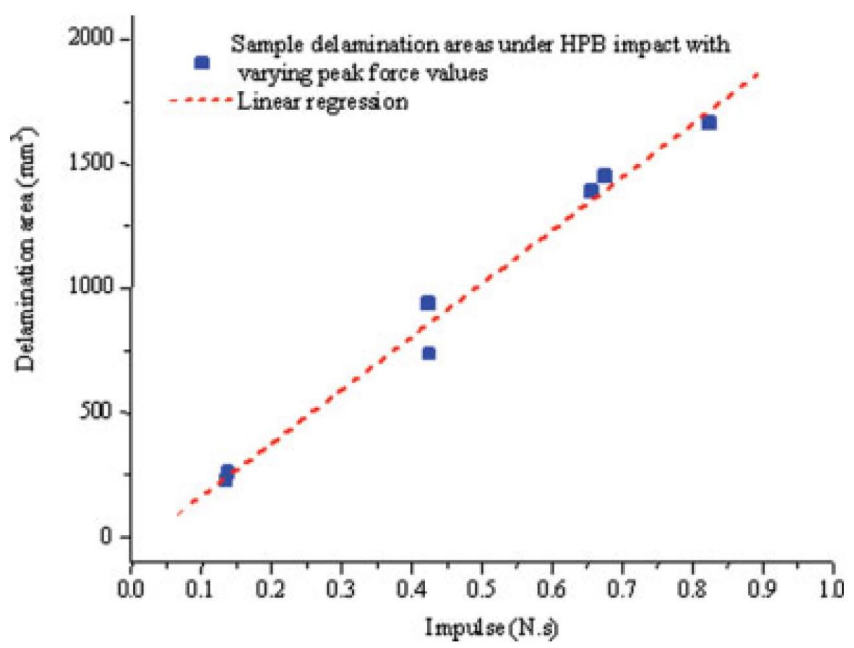

Figure 14. Variation of the sample delamination area versus the impulse of impact force.

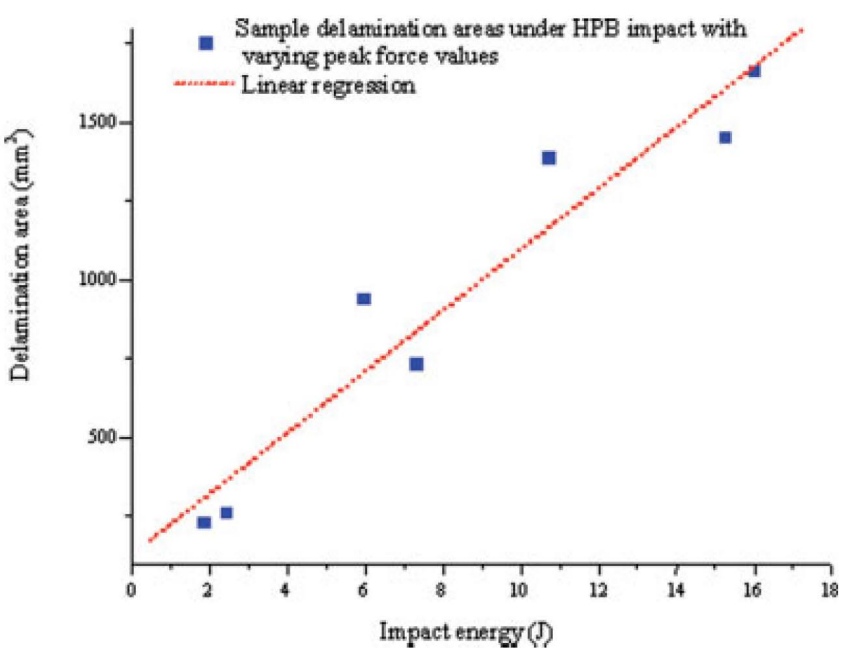

Figure 15. Variation of the sample delamination area versus the transmitted impact energy.

tremely high, up to $50-450 \mathrm{~kW}$ due to the stress-wave with high magnitude propagating within extremely short interval of time ( 0.05 ms). From the linear relations obtained by using linear regression of the experimental data plotted in Figures 13-16, it can be concluded that the peak force of the first impact force pulse can be used for characterizing the force threshold to initiate the delamination damage in the composite laminate under present impulsive loading that is close to $2.6 \mathrm{kN}$. As a result, subjected to impulsive loadings such as ballistic impact or impact exerted by HPB, etc., this linear relation can be employed for characterizing the impact-induced delamination damage in composite laminates and for composite structure design with targeted impact damage tolerance.

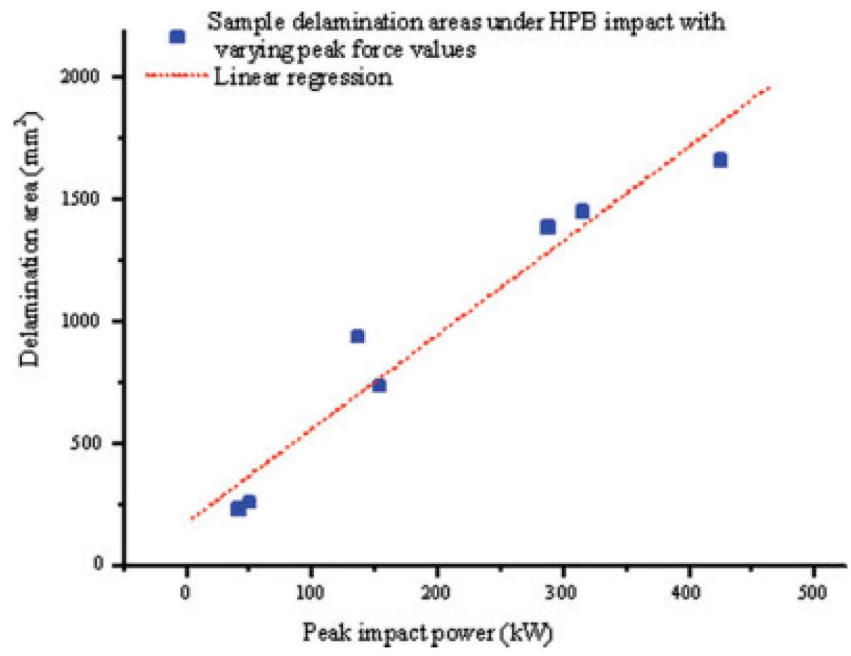

Figure 16. Variation of the sample delamination area versus the peak impact power. 


\section{Concluding Remarks}

In this work, we have performed detailed experimental investigation on the correlation between the impulsive force and the size of impact-induced delamination in a cross-ply composite laminate using a HPB system. A novel ultrasonic pulse-echo reflector technique (PERT) has been developed and used successfully for the characterization of the delamination size in the composite laminate with small thickness. Through the above experimental investigation, the following conclusions can be drawn:

(1) Subjected to impulsive loading within ultra short duration such as those induced by HPB or other ballistic impact, before macroscopic damage and cracking appear in the composite laminate, very good linear correlation exists between the delamination area and the impact force (e.g. the peak force value, peak impact power, impulse, and the transmitted impact energy of the first impact force pulse). The linear relation between the delamination area and the peak value of the first impact force pulse can be regarded as the characteristic relation of the impact tolerance of the composite laminates. This linear relation can be utilized to evaluate the impact damage threshold and to estimate the damage evolution in composite laminates subjected to ballistic impact.

(2) The ultrasonic PERT developed in this study indicates a reliable, effective ultrasonic NDE technique that can be potentially used for evaluating cracks, delaminations, debondings, inclusions, and other inhomogeneities in thin layer systems.

The present method and results can be used for laminate design with impact tolerance requirement and the characterization of impact damage tolerance of composite laminates with varying lay-ups and interface modifications.

\section{Acknowledgments}

The authors would like to thank Professor R. Feng in the Department of Engineering Mechanics at University of Nebraska-Lincoln for helpful discussion and suggestions, and Mr. Mark Clark in the machine shop of the College of Engineering at University of Nebraska-Lincoln for his excellent work in machining the fixture and striker bar. Zuleyha Aslan was a visiting scholar during this experimental investigation in the Department of Engineering Mechanics at University of Nebraska-Lincoln (August 2005-Feburary 2006). Thanks also go to two anonymous reviewers for their enlightening comments on an earlier version. Materials used for this study were provided by the Toray Composites America, CA.

\section{References}

1 S.W. Tsai, Compos. Sci. Technol., 65, 2295 (2005).

2 S. Abrate, ASME Appl. Mech. Rev., 44, 155 (1991).

3 W. J. Cantwell and J. Morton, Composites , 22, 347 (1991).

4 S. Abrate, ASME Appl. Mech. Rev., 47, 517 (1994).

5 S. Abrate, Impact on Composite Structures, Cambridge University Press, Cambridge (1998).

6 R. L. Sierakowski, ASME Appl. Mech. Rev., 50, 741 (1997).

7 J. J. Carrruthers, A.P. Kettle, and A. M. Robinson, ASME Appl. Mech. Rev., 51, 635 (1998).

8 S. P. Joshi and C. T. Sun, J. Compos. Mater., 19, 51 (1985).

9 F. K. Chang, H. Y. Choi, and S. T. Jeng, Mech. Mater., 10, 83 (1990).

10 C. J. Jih and C. T. Sun, J. Compos. Mater., 27, 684 (1993).

11 H. Y. Choi, H. S. Wang, and F. K. Chang, J. Compos. Mater., 26, 804 (1992).

12 G. Zhou, Compos. Sci. Technol., 54, 267 (1995).

13 P. A. Lagace and E. Wolf, AIAA J., 33, 1106 (1995).

14 C. L. Wu and C. T. Sun, Compos. Struct., 34, 21 (1996).

15 M. G. Stout, D. A. Koss, C. Liu, and J. Idasetima, Compos. Sci. Technol., 59, 2339 (1999).

16 G. A. Schoeppner and S. Abrate, Compos. A , 31, 903 (2000).

17 R. Park and J. Jang, Polym. Compos., 21, 231 (2000).

18 Z. Aslan, R. Karakuzu, and B. Okutan, Compos. Struct., 59, 119 (2003).

19 T. W. Shyr and Y. H. Pan, Compos. Struct., 62, 193 (2003).

20 G. Meijer and F. Ellyin, J. Compos. Mater., 38, 2199 (2004).

21 D. S. Liu, J. Compos. Mater., 38, 1425 (2004).

22 J. N. Baucom and M. A. Zikry, Compos. A , 36, 658 (2005).

23 W. A. de Morais, S.N. Monteiro, and J. R. M. d'Almeida, Compos. Struct., 70, 223 (2005).

24 Z. Li and J. Lambros, Compos. A, 31, 537 (2000).

25 N. Liu, G. C. Jin, X. F. Yao, and G. T. Li, Key Eng. Mater., 243/244, 87 (2003).

26 J. W. Gillespie, A. M. Monib, and L. A. Carlsson, J. Compos. Mater., 37, 2131 (2003).

27 Private communication with Rich Thompson at the Tory Composites America, Carlsbad, California.

28 X. F. Wu, Fracture of Advanced Polymer Composites with Nanofiber Reinforced Interfaces, Ph.D. Thesis, University of Nebraska, Lincoln, NE, USA (2003).

29 X. F. Wu and Y. A. Dzenis, Compos. Struct., 70, 100 (2005).

30 X. F. Wu and Y. A. Dzenis, Polym. Compos., 26, 165 (2005). 